\title{
Examining the Ridership Attraction Potential of Bus Rapid Transit: A Quantitative Analysis of Image and Perception
}

Alasdair Cain, Research and Innovative Technology Administration, USDOT Jennifer Flynn, National Bus Rapid Transit Institute (NBRTI)

\section{Abstract}

If public transit is to attract discretionary riders, it must offer high-quality service and convey an attractive image. Although Bus Rapid Transit (BRT) is designed to emulate rail-based transit, there is little quantitative evidence of whether BRT can capture the ridership attraction benefits associated with rail. A combination of focus groups and an attitudinal survey were conducted to assess BRT's ability to replicate the high-quality image and ridership attraction benefits associated with rail, and to quantify the tangible and intangible factors that drive perceptual differences between alternative transit modes. Research was fielded in Los Angeles due to the city's range of rapid transit modes. Overall, findings show that full-service BRT can replicate both the functionality standards and image qualities normally associated with rail, and that even a lower-investment "BRT-lite" service performs remarkably well in terms of overall rating achieved per dollar invested. More generally, results indicate that the image of the surrounding urban area may have greater influence on aggregate perceptions than whether a transit service is based on bus or rail technology. 


\section{Introduction}

Bus Rapid Transit (BRT) is a term used to define a bus-based rapid transit service that attempts to emulate the high-quality service of rail-based transit modes, at a fraction of the capital cost. Initially pioneered in Latin America in the 1970s, BRT in the United States has been steadily gaining traction since the late 1990s and is a modal alternative in nearly every planning study today. Nonetheless, transportation professionals, local government officials, and politicians are still becoming acquainted with the concept and its potential applications. Viewed by BRT advocates as a cost-effective solution to urban mobility problems, the role of BRT is becoming increasingly associated with the wider objective of congestion reduction. It is common knowledge within the transit industry that "image" is important to BRT. Sleek-looking vehicles, rail-like stations, advanced technologies, and a strong brand identity are just a few of the features that help communicate the message that "this is not just a regular bus service." However, despite widespread recognition of its importance, little is actually known about this topic. Can BRT capture the high-quality image of rail systems, and if so, what is the most cost-effective way to accomplish this? How do different BRT design features contribute to overall image? How does image impact ridership attraction? These are some of the questions that led the Federal Transit Administration (FTA) to fund the National Bus Rapid Transit Institute (NBRTI) study, "Quantifying the Importance of Image and Perception to Bus Rapid Transit" (Cain et. al. 2009) (available at http://www.nbrti.org/research. html). This paper summarizes the study and presents its major findings.

\section{Background}

\section{Tangible and Intangible Service Attributes}

The creation of an image and identity separate from local on-street bus operations is an important objective of BRT. Research has shown that if transit is to attract discretionary riders, it must not only offer competitive travel times and high-quality service, but also be complemented by an attractive image. Unfortunately, bus-based public transit in the U.S. suffers from an image problem. Many people perceive the bus as an inferior way to travel, completely at odds with the mobility, convenience, and personal freedom afforded by the automobile. Some of the most common negative views regarding bus service are that it is unreliable, time-consuming, inaccessible, inconvenient, crowded, dirty, and unsafe (Wirthlin Worldwide and FCJandN 2000). 
There is a general impression within the transit industry that rail service is inherently more attractive than bus service and is therefore a necessity for conveying the image of premium service. It has been argued that rail will attract more riders than conventional bus, even if all objectively quantifiable, or "tangible," service attributes (e.g., travel cost, travel time, service frequency) are equal. This perceived advantage is attributed to qualitative and somewhat abstract, or "intangible," factors (e.g., comfort, ride quality, safety) for which rail is thought to be superior. This premise-that difficult-to-measure, subjective factors underlie an innate preference for rail-is the basic rationale for employing bias constants in mode choice modeling. Given that standard models generally include only tangible factors, bias constants are introduced to capture the otherwise unmeasured impact of intangible factors (Ben-Akiva and Morikawa 2002).

As a rapid transit mode that is designed to emulate rail, BRT aims to capture at least some of the ridership attraction benefits associated with this high-investment mode. Although rail has an advantage over conventional bus service in terms of ridership attraction potential, there is little quantitative information on how BRT compares to rail in this regard. However, research by Ben-Akiva and Morikawa (2002) indicates that when quantifiable service characteristics are equal, riders may find high-quality bus alternatives equally attractive to rail transit for CBD-oriented commutes. Currie (2005) considers tangible and intangible factors in his argument that BRT and rail should generate equal ridership when the total trip attributes of both alternatives (travel time, cost, ride quality, transfers, and quality facilities) are equal. Henke (2007) draws on the findings of several different studies to conclude that up to one third of median ridership gain observed across six new BRT systems could not be explained by quantifiable service improvements, and that most of this unexplained aspect was due to brand identity.

Jointly, these studies lay the theoretical framework for the research presented in this paper: that service attributes (both tangible and intangible), rather than an innate preference for a particular mode or technology, explain the relative passenger attractiveness of rail and BRT. Thus, we hypothesized that for BRT to attract riders at a level similar to rail, it must be comparable to rail in terms of both tangible and intangible service attributes. To investigate this issue, we designed a study to (1) assess BRT's ability to convey the high-quality image typically associated with rail-based transit and (2) examine and quantify the tangible and intangible factors that drive perceptual differences between alternative transit modes. 


\section{Defining BRT: From BRT-Lite to Full-Service BRT}

When considering the image of BRT, it is important to note that the term BRT covers a wide spectrum of different applications. Although there are many different ways to subdivide these applications, BRT is often classified on the basis of running way type, which plays a central role in determining the investment cost and performance of the system.

The BRT mode is often viewed as bridging the gap between the local bus system and light rail transit; however, this gap is significant and covers a wide range of applications." At the lower end of the investment spectrum are the "BRT-lite" systems (also known as "rapid bus" or "low-level BRT") that typically run in mixed traffic, using relatively low-cost applications such as traffic signal priority (TSP), intersection queue jumps, headway-based schedules, and far-side stops to improve commercial speeds and reliability. One of the best known and most successful examples of this approach is the Metro Rapid in Los Angeles.

BRT systems often feature some form of exclusive running way to guarantee high commercial speeds and reliability during peak periods. The most basic form is a shoulder bus lane, which can often be provided at minimal cost by simply restriping an existing lane or using a lane formerly designated for parking or loading and unloading. An added advantage of the bus lane approach is that it may be applied to specific route sections only or to operate during specific time periods, such as the morning and evening peaks.

Median bus lanes and median busways represent the next level up in terms of performance and investment. Locating the bus lane in the median tends to reduce the number of conflicts caused by side-street access, illegally parked cars, and other obstructions, thus providing higher performance levels. While typically more expensive than median bus lanes, median busways provide the added advantage of physically separating the running way from other traffic.

At the high end of BRT investment and performance are exclusive busways. Often described as "full-service" BRT or "high-level BRT," these require obtaining the necessary right-of-way, which can often be achieved by using existing transit alignments such as abandoned rail lines. Although complete grade separation is nearly

\footnotetext{
${ }^{1}$ The authors recognize that the "conventional" view of BRT as simply a low-cost alternative to light rail transit (LRT) is an oversimplification. Recent research has shown that BRT and LRT are distinctly different modes, each with its own strengths and weaknesses. Indeed, it has been argued that BRT can match or even surpass the performance of LRT under certain circumstances. For more detailed information on this topic, please see Hoffman (2008).
} 
impossible, exclusive busways are designed to minimize the number of at-grade intersections. Modern applications of this high-investment approach generally feature amenities more commonly associated with rail systems, including highquality permanent stations, level boarding, off-board fare payment, and stylized vehicles (although these features are increasingly being provided at lower levels of investment as well). An example of this approach is the Metro Orange Line in Los Angeles.

On the matter of defining BRT, it should be noted that recent federal legislation under the Moving Ahead for Progress in the 21st Century Act (MAP-21) creates two fundamental classes of BRT projects: corridor-based and fixed-guideway. Both types of BRT must demonstrate substantial transit investment through features such as defined stations, TSP, short headways, and bidirectional service for a significant portion of weekday and weekend service. However, while fixed-guideway BRT must operate in a dedicated right-of-way during peak hours for the majority of the project length, there is no such provision for corridor-based BRT projects. Considering the wide spectrum of BRT applications discussed above, BRT-lite would typically equate with corridor-based BRT, while the exclusive running way applications, if constituting a majority of the project, would fall under fixed-guideway BRT.

\section{Study Methodology}

The study was designed to address the following core questions:

- Do people perceive alternative rapid transit modes differently?

- If differences exist, where do they originate?

- To what extent can differences in ridership attraction potential be attributed to individual tangible and intangible service attributes?

- What variations exist with regard to socio-economic/geographic factors?

The project was designed around two market research exercises: a series of focus groups, followed by an attitudinal survey. Los Angeles was chosen as the location for these exercises because it features many different rapid transit modes, including BRT-lite (Metro Rapid) and full-service BRT (Orange Line), as well as light rail transit (Blue and Gold Lines) and heavy rail transit (Red Line). Following is a description of the different transit modes in Los Angeles that were considered in this study. Table 1 provides summary statistics for each mode. 
Table 1. Summary Statistics for Each LA Transit Mode1

\begin{tabular}{|c|c|c|c|c|c|c|}
\hline & Local Bus & $\begin{array}{c}\text { Metro } \\
\text { Rapid }^{2} \\
\text { (BRT-lite) }\end{array}$ & $\begin{array}{l}\text { Blue Line } \\
\text { (LRT) }\end{array}$ & $\begin{array}{l}\text { Orange } \\
\text { Line } \\
\text { (BRT) }\end{array}$ & $\begin{array}{l}\text { Gold Line } \\
\text { (LRT) }\end{array}$ & $\begin{array}{l}\text { Red Line } \\
\text { (HRT) }\end{array}$ \\
\hline Opening year & & 2000 & 1990 & 2005 & 2003 & 1993 \\
\hline $\begin{array}{l}\text { Av. weekday board- } \\
\text { ings }\end{array}$ & 850,553 & 242,000 & 74,803 & 20,138 & 22,543 & 140,943 \\
\hline $\begin{array}{l}\text { Annual boardings } \\
\text { (FY2008) }\end{array}$ & $308.35 M$ & $71.72 M$ & $24.56 \mathrm{M}$ & $7.46 \mathrm{M}$ & $6.58 M$ & $43.59 M$ \\
\hline System length (mi) & $2,831^{3}$ & 369 & 22 & 14 & 13.7 & 17.4 \\
\hline Capital cost & $\$ 206.2 M^{4}$ & $\$ 123.3 M$ & $\$ 877 M$ & $\$ 330 M$ & $\$ 859 M$ & $\$ 4.5 B$ \\
\hline Capital cost $/ \mathrm{mi}$ & $\$ 91,228$ & $\$ 354,798$ & $\$ 39.9 M$ & $\$ 23.6 M$ & $\$ 62.7 \mathrm{M}$ & $\$ 258.6 M$ \\
\hline Capital cost (2005\$) & $\$ 206.2 M^{6}$ & $\$ 123.3 M^{5}$ & $\$ 1,300 M$ & $\$ 330 M$ & $\$ 912 M$ & $\$ 5.6 \mathrm{~B}$ \\
\hline $\begin{array}{l}\text { Capital cost/mi } \\
(2005 \$)\end{array}$ & $\$ 91,228^{6}$ & $\$ 354,798^{6}$ & $\$ 59.1 M$ & $\$ 23.6 M$ & $\$ 66.6 M$ & $\$ 321.8 M$ \\
\hline \# of stops/stations & 15,424 & 543 & 22 & 14 & 13 & 16 \\
\hline $\begin{array}{l}\text { \# of rail cars/buses } \\
\text { in fleet }\end{array}$ & $2,261^{6}$ & 452 & 69 & 30 & 24 & 104 \\
\hline Peak headway (mins) & varied & $2.5-10$ & $5-7$ & $4-5$ & 10 & $4-6$ \\
\hline $\begin{array}{l}\text { Off-peak headway } \\
\text { (mins) }\end{array}$ & varied & $10-20$ & $12-20$ & $10-20$ & $12-20$ & $6-19$ \\
\hline $\begin{array}{l}\text { Weekday service } \\
\text { span (hrs) }\end{array}$ & varied & 15 & 22.1 & 21.8 & 21.3 & 20.9 \\
\hline Service area & $\begin{array}{l}\text { City-wide } \\
\text { network }\end{array}$ & $\begin{array}{l}\text { City-wide } \\
\text { network }\end{array}$ & $\begin{array}{l}\text { South L.A., } \\
\text { Watts, } \\
\text { Compton, } \\
\text { L. Beach }\end{array}$ & $\begin{array}{c}\text { South San } \\
\text { Fernando } \\
\text { Valley }\end{array}$ & $\begin{array}{l}\text { Highland } \\
\text { Park, } \\
\text { South } \\
\text { Pasadena }\end{array}$ & $\begin{array}{c}\text { Downtown } \\
\text { L.A., } \\
\text { Hollywood, } \\
\text { N. Hollywood }\end{array}$ \\
\hline
\end{tabular}

${ }^{1}$ Statistics current as of 2009, courtesy of LACMTA staff and website www.metro.net.

${ }^{2}$ Metro Rapid data are for 25 lines operated by LACMTA only.

${ }^{3}$ From FY08 National Transit Database (NTD) Motor Bus (MB) Directly Operated (DO) Directional Route miles from S-10 Report. The Local Bus data are annual NTD number minus Metro Rapid Bus stated amount in matrix.

${ }^{4}$ Total annual capital project cost from LACMTA FY09 Budget Book for projects in following categories: Bus Acquisition, Bus Facility Improvements, Bus Maintenance, and ITS (3 projects TOAST, ATMS and TAP Clearinghouse).

${ }^{5}$ The local bus and Metro Rapid capital costs are an aggregation of costs accrued incrementally over time. Thus, they have not been adjusted to 2005 dollars.

${ }^{6}$ From FY08 National Transit Database (NTD) Motor Bus (MB) Directly Operated (DO) Revenue Vehicle A-10 report total buses owned minus Metro Rapid Bus stated amount in matrix. 


\section{Metro Local}

Metro Local is the conventional bus service that operates throughout the city. Buses are distinguished by their bright orange color, although a number of older buses remain white with an orange stripe.

\section{Metro Rapid (BRT-Lite)}

The Metro Rapid is a well-known example of the lower-investment approach to BRT that operates in mixed traffic, known as BRT-lite or Rapid Bus. Delays are minimized through the use of headway-based schedules, higher-frequency service, a simplified route design, more widely-spaced stops, and signal priority measures. Other elements include low-floor buses, a unified brand identity, and enhanced stops with amenities such as lighting, canopies, and real-time information. Growing steadily since two initial pilot corridors were opened in 2000, the Metro Rapid now consists of a 450-mile network of routes throughout the city (see Figure 1). While the Metro Rapid service is provided primarily by standard $40 \mathrm{ft}$ vehicles, some $60 \mathrm{ft}$ articulated vehicles are now used on the highest-demand routes.

\section{Orange Line (Full-Service BRT)}

The Metro Orange Line opened in 2005 as one of the first full-service BRT systems in the United States. At the time of this study, it comprised a 14-mile dedicated busway running east-west through the San Fernando Valley and connecting to the Red Line at its eastern terminus in North Hollywood. In June 2012, the busway was extended four miles northward from Canoga Station to the Chatsworth Metro Link commuter rail station. The Orange Line features $60 \mathrm{ft}$ articulated vehicles, permanent stations, level boarding, off-board fare payment, and headway-based schedules. Vehicles are powered by compressed natural gas (CNG) and feature aerodynamic styling, panoramic windows, low floors, wide aisles, and three extrawide doors. Stations offer various amenities, including bicycle racks and lockers, covered seating, ticket vending machines, telephones, and enhanced lighting. To give the Orange Line a premium service image, Metro has branded the route as part of the city's rapid transit network (see Figure 2). 


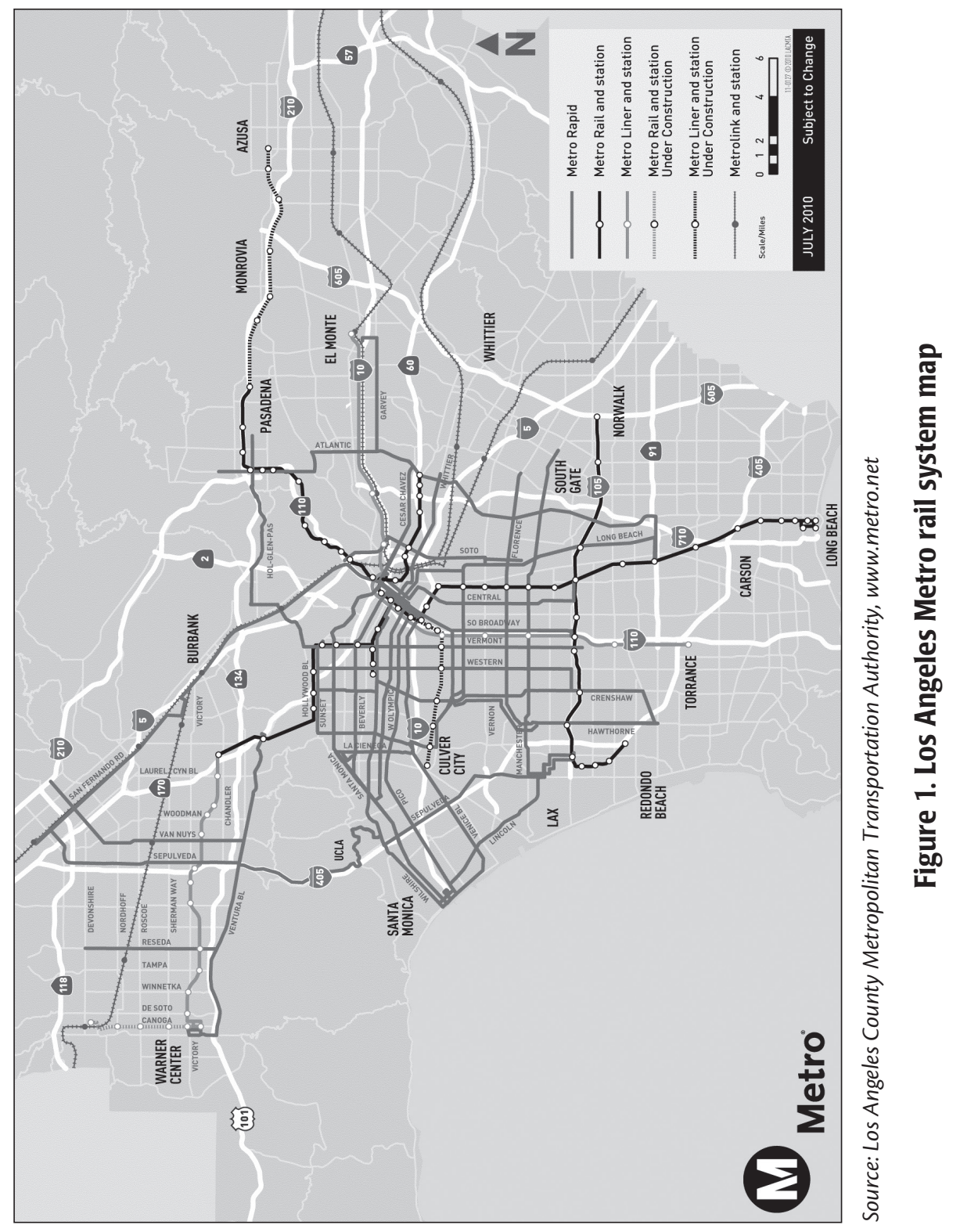




\section{Go Metro}

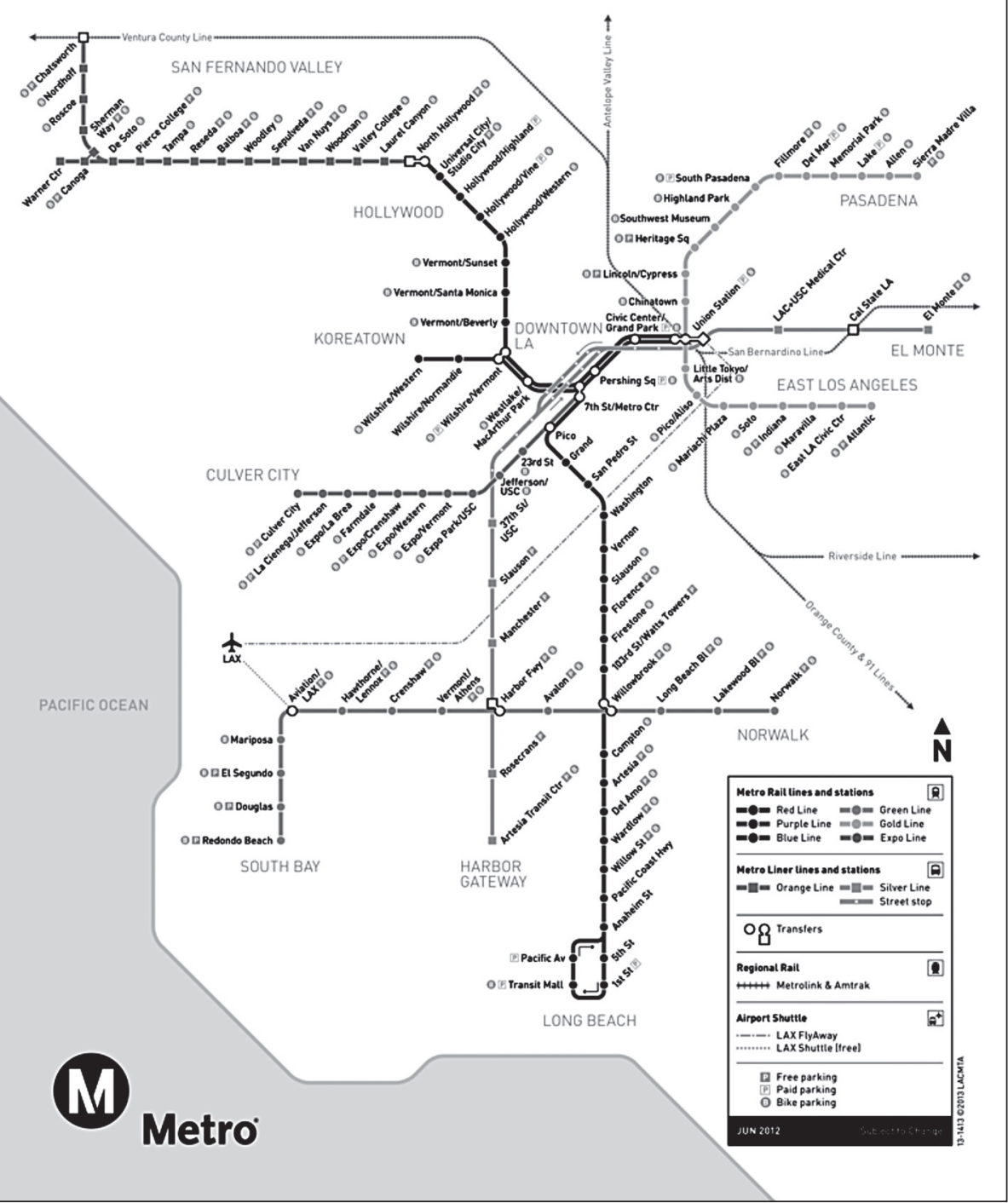

Source: Los Angeles County Metropolitan Transportation Authority, www.metro.net

\section{Figure 2. Metro Rapid network map}




\section{Blue Line (Light Rail)}

The first and longest of MTA's modern light rail lines, the Metro Blue Line runs north-south for 22 miles between downtown Los Angeles and downtown Long Beach. Opened in 1990, the line serves 22 stations and traverses much of the densely-populated area through South Los Angeles, Watts, Willowbrook, Compton, and Long Beach, which includes some of the most economically-deprived areas of the city.

\section{Gold Line (Light Rail)}

The Metro Gold Line opened in 2003. At the time of this study, it spanned 13.7 miles from eastern Pasadena to downtown Los Angeles, along a disused railroad right-of-way adjacent to the heavily-congested Pasadena and Foothill freeways. The service has since been extended six miles eastward from its original terminus at Union Station in downtown to Atlantic Station in East Los Angeles, bringing the total line length to 19.7 miles.

\section{Red Line (Heavy Rail)}

The Metro Red Line, the highest ridership rail line in Los Angeles, operates solely underground and spans 17.4-miles, providing high-speed service to the city's most densely-populated areas. Service runs from downtown Los Angeles to North Hollywood via the jewelry, retail, and financial districts and the neighborhoods of Westlake and Hollywood. The eastern terminus at downtown's Union Station provides connections to AmTrak, Metro Local, Metro Rapid, and the Metro Gold Line; the Metro Blue Line can be accessed at 7th St/Metro Center; transfers to the Metro Orange Line BRT can be made at the end of the line in North Hollywood.

\section{Focus Groups}

\section{Objectives}

The focus group exercise was designed to address the following objectives:

- Explore public attitudes toward the different rapid transit modes and the private auto

- Gain an understanding of the influence of urban context and socio-economic factors on public perceptions of different rapid transit modes and the private auto

- Identify the tangible and intangible factors that influence mode choice decisions 


\section{Methodology}

The sampling methodology was designed to focus on people with viable modal alternatives for their everyday travel needs, making use of a transit market segmentation concept developed by Krizek and El-Geneidy (2007). Four market segments were defined. People using transit were divided into "choice users" (people with access to a private vehicle) and "captive users" (people without other means of transportation). People not using transit were divided into "potential users" (people that could use transit but choose not to) and "auto users" (people without a transit option for their trips, also known as "auto captive").

A local market research firm was hired to perform sample recruitment and provide a venue for the focus groups, which were conducted in the Universal City area of Los Angeles in November 2007. The authors were responsible for group moderation and qualitative data analysis. Group sampling criteria were designed to ensure diversity in terms of age, income, ethnicity, and gender. Most of the participants were choice users of one or more of the different rapid transit modes, although a smaller sample of potential users also was recruited. Thus, all focus group participants had access to a private vehicle. This was to ensure that the people recruited for the focus groups had some level of mode choice available to them in their daily travel behavior. Sample quotas were defined to ensure representative choice users of each of the following modes: local bus, Metro Rapid (BRT-lite), Orange Line (fullservice BRT), Gold/Blue Line (LRT), and Red Line (HRT), as well as representatives of the potential user group. People who were captive, either to transit or the automobile, were screened out of the study.

\section{Identification of Tangible and Intangible Service Attributes}

Qualitative analysis of the focus group transcripts provided a rich source of information on perceptions of life and travel in the Los Angeles metropolitan area and detailed views on each of the travel modes included in the study. For more information on these issues, please refer to the final project report document. The focus group information also allowed the authors to identify a large number of service attributes affecting overall modal perceptions. Most of the tangible factors were previously identified in the literature as standard inputs of transit travel demand and mode choice models, although reliability was identified in some literature sources as one of the intangible factors typically captured by mode bias constants.

It was found that each focus group participant typically mentioned a range of both tangible and intangible factors when comparing the different modes with each other and with private vehicle use. Regular transit users tended to be more 
focused on the tangible attributes such as service span, frequency, and cost, while less frequent users were more likely to cite intangible attributes (service is unsafe, buses are overcrowded or uncomfortable).

Following the factor identification process, factors were separated into tangible and intangible variable groups and then synthesized into 14 core variables for further analysis in the attitudinal survey. These variables, as presented in the survey, are described in Table 2.

\section{Attitudinal Survey}

The survey exercise was designed to quantify the relative importance of the different tangible and intangible factors identified in the focus groups and to determine the contribution of each to the overall ridership attraction potential of the different rapid transit modes. A local Los Angeles market research firm was hired to work with the study authors in the development of the survey methodology and survey instrument, to conduct the survey, and to analyze the survey data. The survey was fielded in the fall of 2008.

\section{Table 2. Identified Tangible and Intangible Service Attributes}

\begin{tabular}{|l|l|}
\hline \multicolumn{1}{|c|}{ Tangible Factors } & \multicolumn{1}{c|}{ Intangible Factors } \\
\hline $\begin{array}{l}\text { - Travel Cost - transit fares, plus related costs } \\
\text { like parking }\end{array}$ & $\begin{array}{l}\text { - Safety while riding the service - safety } \\
\text { - from accidents and/or crime }\end{array}$ \\
- Door to door travel time & Comfort while riding - seats available, tem- \\
- Frequency of Service - how often the & perature, smooth ride, cleanliness, etc. \\
service runs & Safety at the station/stop - safety from \\
- Hours of service - how early or late service & accidents and/or crime \\
runs, and/or weekend hours & - Comfort at the station/stop - shelter from \\
- Convenience of service - goes where you & weather, amenities, etc. \\
need to go/parking availability & - Customer service - provided by drivers and \\
- Reliability of service - does the service run & other transit service staff \\
on time? & - Ease of service use - clear service info, \\
& routes easy to figure out, etc. \\
& - Other riders - feeling secure/at ease/com- \\
& patible with others using service \\
& Avoid stress/cost of car use - traffic, park- \\
& ing, accidents, tickets, etc. \\
\hline
\end{tabular}

\section{Survey Methodology}

A sampling methodology was developed to yield valid and reliable demographic profiles that could be generalized to the universe of riders of each transit mode 
and for non-riders ( $\pm 5 \%$ accuracy at the $95 \%$ confidence level). Two corridors were selected that have access to a majority of the different modes being rated. The San Gabriel Valley Corridor offered parallel light rail, express bus (Gold Line/BRT-lite), and local bus service. The San Fernando Valley Corridor offered parallel high-level BRT service (Orange Line), express bus, and local service. In addition, both corridors connect to the central business district and to the Red Line, which is the heavy-rail mode evaluated in this study.

A total sample of 2,390 respondents was obtained, including approximately 400 respondents for each of the 6 identified transit modes, obtained through on-board surveys (with telephone call-back for incomplete surveys) and a Random-DigitDialing telephone survey of approximately 400 non-transit users. Respondents were categorized into the four market segments identified by Krizek and ElGeneidy (2007). Approximately two-thirds (66\%) of transit users were identified as transit captive, whereas non-users were nearly evenly split into auto captive (47.9\%) and potential users (52.1\%).

While the study's ultimate goal was to assess how perceptions of the different travel modes were linked to ridership attraction potential, it was recognized that it would be difficult to do this directly, due to the geographically dispersed nature of the study modes (for example, respondents residing in south or west Los Angeles would be unlikely to ever ride the Gold Line, no matter how positive their perceptions of this service). To overcome this, the overall rating assigned by respondents to each mode (ranging from "very poor" to "very good") was used as a proxy for ridership attraction potential, as it was assumed that respondents would be able to provide a general opinion of any service they were asked about, provided they were aware of it, even if they were not in a position to use it. Those unaware of any particular service were not asked for their opinion of it.

\section{Study Findings}

Statistically significant differences were observed in the mean overall ratings achieved by each of the alternative transit modes, which were separated into four distinct tiers. These four tiers are shown below, ordered from lowest to highest in terms of average overall rating achieved: 
- Tier 1: Local bus service (mean overall rating of 3.70)

- Tier 2: Metro Rapid BRT and Blue Line LRT (mean overall ratings of 4.01 and 3.98, respectively)

- Tier 3: Orange Line BRT and Gold Line LRT (mean overall ratings of 4.08 and 4.06 , respectively)

- Tier 4: Red Line HRT (mean overall rating of 4.18)

It was noted that level of investment appeared to be an influencing factor, with the lowest and highest investment modes (the local bus and the Red Line HRT) achieving the lowest and highest mean ratings respectively. Thus, the mean overall ratings were compared against the actual level of investment associated with each mode, defined as capital cost per mile in 2005 dollars. $^{2}$

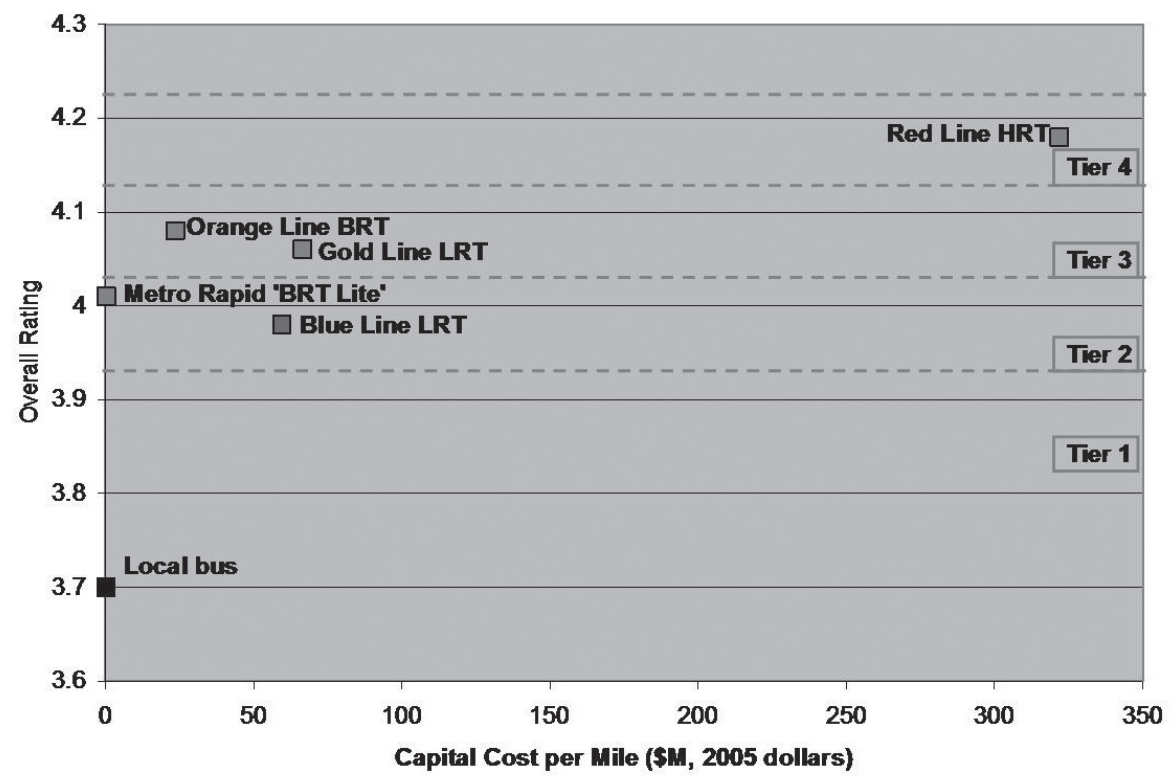

\section{Figure 3. Overall rating of each transit mode versus capital cost per mile}

\footnotetext{
${ }^{2}$ It recognized that capital costs are only one aspect of the overall cost of a transit investment, and that a more accurate comparison of the cost effectiveness of different types of transit investment would consider "lifecycle cost," which includes capital costs plus operational costs summed over the lifetime of the system. Capital costs have been used here due to difficulties experienced in finding comparable operational cost data for each of the modes under consideration.
} 
This analysis revealed a large disparity in investment level, with the Red Line costing approximately 1,000 times more per mile than the local bus service and Metro Rapid. For the Tier 2 services, it was observed that the Metro Rapid achieved a slightly higher rating than the Blue Line (although statistically, these two are considered to have the same rating), for a fraction of the investment cost $(\$ 0.355 \mathrm{M}$ per mile versus $\$ 59.1 \mathrm{M}$ per mile). Given that the investment level of the Metro Rapid is much closer to that of the local bus than to any of the other modes, it must be concluded that the Metro Rapid performed remarkably well in terms of overall rating achieved per dollar of investment, and thus represents a very cost-effective form of BRT.

Considering the Tier 3 services, it was observed that the Orange Line achieved a slightly higher rating than the Gold Line (though again, in statistical terms these two are rated the same) for approximately one-third of the investment cost. This indicated that the Orange Line also performs well in overall rating per dollar of investment, although not to the dramatic level of the Metro Rapid. Overall, these findings showed that BRT, even in its lower-investment form, can compete with rail-based transit (at least in the perception of the general public) in return for lower capital cost investments.

Aside from the two obvious extremes of the local bus and the Red Line, the ratings achieved by the remaining transit services were not simply proportional to respective levels of investment; clearly, other variables were involved. First, why were the Blue and Gold Lines rated differently, even though they are the same mode, at approximately the same level of investment? Further investigation showed that the higher overall rating achieved by the Gold Line was attributed primarily to higher ratings for key intangible variables: safety (both at the station and onboard) and perceptions of other riders. Interestingly, these same intangible variables were also chiefly responsible for the Orange Line achieving a higher overall rating than the Blue Line. The focus group work suggested that these results speak to the wider issue of urban context. The Blue Line runs through some of the most economicallydeprived areas of the city, while the Gold and Orange lines serve relatively affluent areas; thus, it appears that these differences in urban context are largely responsible for the discrepancy in overall rating between these modes. Furthermore, it appears that urban context is more influential in determining overall perceptions than whether the service is rail- or bus-based. Since the Orange Line achieved similar ratings to the Gold Line for both tangible and intangible attributes, the authors concluded that full-service BRT is capable of replicating both the functionality 
standards and image qualities normally associated with LRT, at least in the perception of the general public. In the words of one focus group participant, "It's not a bus, it's a train-bus."

It was also important to understand how the two different forms of BRT, representing opposite ends of the BRT investment spectrum, are viewed by the public. It was found that the Orange Line's significantly higher overall rating originated in higher ratings on both the tangible and intangible attributes, although by far the largest single difference was in relation to station comfort. That the Orange Line received superior ratings for both tangible and intangible attributes implies a greater likelihood of success in attracting the coveted "potential rider" market (those that could ride transit but choose to travel by private auto instead). However, while the Orange Line is perceived as superior, it should be noted that the Metro Rapid achieved an overall rating that was only slightly lower, while costing around 100 times less per mile to provide.

Finally, it was important to understand why the Metro Rapid BRT-lite system achieved significantly higher ratings than the local bus system, although both run in mixed traffic. The most significant differences were found in relation to travel time, followed by frequency and reliability. So whereas the Metro Rapid also achieved higher ratings on important intangible attributes like safety and comfort, it appears that the attraction of BRT-lite over local bus relates to higher perceived levels of functional service performance.

Some progress was made in understanding the influence of different tangible and intangible factors on overall perceptions of each mode. Figure 4 illustrates the average importance rating assigned to each tangible and intangible factor. In terms of importance, the tangible attributes of reliability and service frequency received the highest ratings, along with the intangible attribute of ride safety. These were closely followed by the tangible attribute of service span and the intangible attribute of station safety. Overall, it is clear that the public considers both tangible and intangible factors in determining their overall opinion of alternative transit services. 


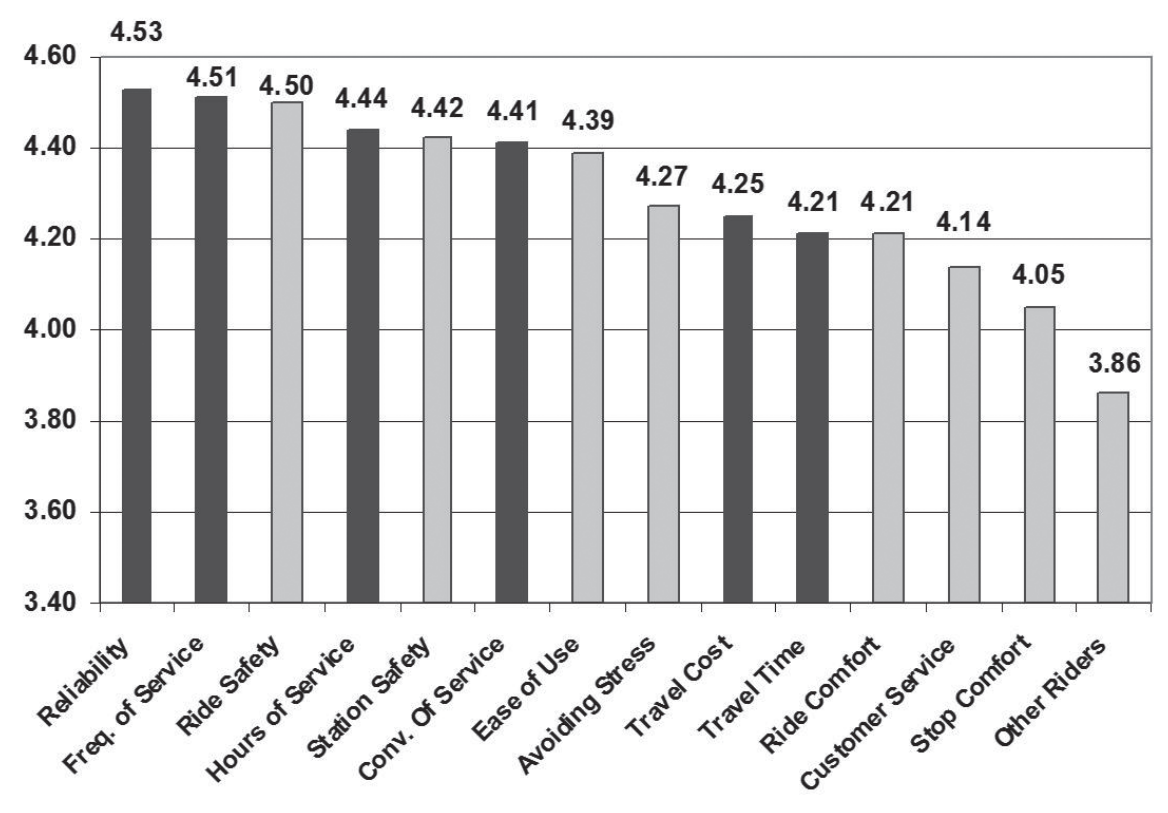

Figure 4. Aggregate importance rating for each tangible and intangible factor

Although several different model formulations were tested, the index regression model was found to provide the most consistent explanatory power in linking individual service attributes (independent variables) to the mean overall ratings achieved by each mode (dependent variable). The model showed that local bus ratings were more heavily influenced by the tangible attribute group that included travel time, service span, and service frequency, while the rail modes were impacted more by the intangible safety/comfort factor group. Further research could test the hypothesis that functionality is more influential in the attractiveness of lower-investment bus-based services, which tend to focus on "no-frills" provision of basic mobility, while intangible aspects like safety and comfort are more influential in the attractiveness of higher-investment BRT and rail-based modes. It is conceivable that once basic mobility needs have been met, riders turn their attention to intangible aspects like safety and comfort. Such behavior would be consistent with Maslow's well-known Hierarchy of Needs theory (1943), in which basic human physiological needs must be met before higher-level needs can be considered. Perhaps the same is true of mobility. 


\section{Conclusions}

With regard to the four core questions posed at the study's inception, the following conclusions are provided:

1. Do people perceive alternative rapid transit modes differently? This study found that the general public does perceive alternative rapid transit modes differently, with the modes being separated into four distinct statistically different tiers in terms of mean overall rating achieved. Furthermore, BRT achieved overall ratings that were equivalent to light rail transit, and thus appears to be capable of capturing the image qualities normally associated with this higher-investment mode. The study also suggests that BRT, particularly a BRT-lite service like the Metro Rapid, offers a highly cost-effective form of transit investment.

2. If differences exist, where do they originate? As expected, the study showed that the level of investment associated with each mode clearly plays a role. Less expected was the indication that urban context may also have a significant influence, by directly impacting intangible service attributes like perceptions of safety. Indeed, it appears that the image of the urban area through which a transit service runs may be more important in determining aggregate perceptions than whether the service is rail- or bus-based. Thus, improving the image (most importantly, perceptions of safety) of the surrounding urban area may also improve the ridership attraction potential of a transit service.

3. To what extent can differences in ridership attraction potential be attributed to individual tangible and intangible service attributes? In addition to level of investment and urban context, a range of other factors clearly play a role in determining the ridership attraction potential (or, in this case, mean overall rating) achieved by each mode. This study found that public perceptions are driven by combinations of a wide range of different tangible and intangible service attributes, including tangible attributes like reliability, service frequency and span, along with intangible attributes like safety and comfort.

4. What variations exist with regard to socio-economic/geographic factors? The study found that the overall ratings for each transit mode, and the level of importance attributed to each tangible and intangible factor, were generally unaffected by the range of typical socio-economic/demographic variables such as gender, age, and income. The importance of the different tangible and 
intangible attributes were cross tabulated across the various demographic variables and, due to the large sample size, most of them produced statistically significant differences, although they did not provide any actionable insights. Cost was rated more important by transit captives than by the other three market segments, and this difference was statistically significant. For transit choice riders, travel time was rated higher than for the other groups, and this difference was also statistically significant. It is not remarkable that cost would be more of an issue for transit captives, who tend to have lower-incomes, while travel time would be more of an issue for transit choice riders, who have the option of traveling by private auto.

In conclusion, it should be noted that Los Angeles was chosen as the location for this study because it features many different rapid transit modes in fairly close proximity, including full-service BRT, BRT-lite, light rail, and heavy rail. However, Los Angeles is a vast, auto-centric metropolitan area with some of the worst levels of traffic congestion in the country and, therefore, cannot be assumed to represent a typical North American city. Also, it must be noted that this study used mean overall ratings as a proxy for ridership attraction potential. Further research is required to verify whether this is a reasonable assumption and whether the study findings can be generalized to other urban areas. Future research work could expand upon this study's findings by focusing more on the important "potential user" group.

\section{Acknowledgments}

This research work was undertaken and completed while a co-author was a Senior Research Associate at CUTR/NBRTI/USF. The opinions, findings and conclusions expressed in this publication are those of the authors and do not necessarily reflect the views, positions or policies of the Research and Innovative Technology Administration or the U.S. Department of Transportation.

\section{References}

Ben-Akiva, M., and T. Morikawa. 2002. Comparing ridership attraction of rail and bus. Transport Policy 9(2): 107-116.

Cain, A., G. Darido, M. Baltes, P. Rodriguez, and J. Barrios. 2006. Applicability of Bogota's TransMilenio BRT System to the United States. No. FL-26-7104-01. 
Cain, A., J. Flynn, and M. McCourt. 2009. Quantifying the importance of image and perception to bus rapid transit. National Bus Rapid Transit Institute, Center for Urban Transportation Research. FTA-FL-26-7109.2009.3.

Currie, G. 2005. The demand performance of bus rapid transit. Journal of Public Transportation 8(1): 41-55.

Henke, C. 2007. How customer-appealing design and branding win new riders: Data and best practices. Annual APTA Bus and Paratransit Conference, Nashville.

Hoffman, A. 2008. Advanced network planning for bus rapid transit: The "quickway" model as a modal alternative to "light rail lite." No. FL-26-7104-04.

Krizek, K., and A. El-Geneidy. 2007. Segmenting preferences and habits of transit users and non-users. Journal of Public Transportation 10(3): 71-94.

Maslow, A. H. 1943. A theory of human motivation. Psychological Review 50(4): 370-396.

Wirthlin Worldwide and FCJandN. 2000. TCRP Report 63: Enhancing the visibility and image of transit in the United States and Canada. Transit Cooperative Research Program, National Research Council, Washington, DC.

\section{About the Authors}

AlasdaIR CAIN (alasdair.cain@dot.gov) is a Transportation Specialist at the Research and Innovative Technology Administration (RITA), United States Department of Transportation.

JenNIfeR FLynN (flynn@cutr.usf.edu) is a Senior Research Associate at the National Bus Rapid Transit Institute (NBRTI) at the Center for Urban Transportation Research (CUTR) at the University of South Florida. 